\title{
Future Screening for Incipient Alzheimer's Disease - The Influence of Prevalence on Test Performance
}

\author{
Niklas Mattsson Henrik Zetterberg \\ Institute of Neuroscience and Physiology, Department of Neurochemistry and Psychiatry, \\ The Sahlgrenska Academy at University of Gothenburg, Mölndal, Sweden
}

\section{Key Words}

Biomarkers · Alzheimer's disease, prevalence .

Diagnostic test

\begin{abstract}
Much effort has been made to identify and verify diagnostic biomarkers for early stage Alzheimer's disease (AD). The need for this is often advocated by possible future diseasemodifying treatments, likely to be most effective if initiated early in the disease process. Since the neurodegenerative process probably starts many years before the first onset of symptoms, such future drugs are likely to invoke a need for screening presymptomatic individuals. Here, we speculate on the performance of currently available AD biomarkers in hypothetical screening programs of different designs. We note that many diagnostic tests will have an excellent ability to exclude upcoming AD. However, even the best tests will suffer from poor positive predictive values given the relatively low disease prevalence in populations with no or very few symptomatic individuals, also when taking future converters to $A D$ into account. The magnitude of this problem, which is common among most screening programs, will depend on the efficacy, safety and cost of the future anti-AD drugs. A number of tentative solutions to the problem, apart from better tests, are discussed.
\end{abstract}

Copyright $\odot 2009$ S. Karger AG, Basel
This text deals with the implications of probable future disease-modifying Alzheimer's disease $(\mathrm{AD})$ treatment on diagnostic testing. It is widely presumed that disease-modifying treatments with $\gamma$ - and $\beta$-secretase inhibitors or vaccination regimes will have optimal effect if initiated early in the disease process $[1,2]$. Much focus has thus been directed on patients with mild cognitive impairment (MCI), a syndrome characterized by cognitive impairment beyond the age-adjusted norm, but not severe enough to fulfill the criteria for dementia [3]. The annual rate of AD diagnosis in amnestic MCI patients is about $15 \%[4,5]$. However, some MCI cases have a benign clinical course with no symptom progression, while others prove to have other types of dementia. A primary diagnostic challenge to clinicians will therefore be to identify MCI patients with incipient $\mathrm{AD}$, requiring an immediate start of treatment. For this purpose, several studies have tested the diagnostic accuracy of imaging techniques and cerebrospinal fluid (CSF) levels of $\beta$-amyloid $1-42$ and $\tau$ in an early stage of the disease [6-12]. These biomarkers have good or excellent sensitivity and specificity of $85-95 \%$ for incipient AD in MCI populations. While these figures are of interest to researchers, publichealth policymakers and the diagnostics industry, they are of little use to clinicians. Sensitivity and specificity look backward at results gathered over time [13], but clinicians have to interpret test results to those tested with

\section{KARGER}

Fax +4161306 1234 E-Mail karger@karger.ch www.karger.com
Dr. Niklas Mattsson

Clinical Neurochemistry Laboratory

Sahlgren's University Hospital/Mölndal

SE-431 80 Mölndal (Sweden)

Tel. +46 31343 2377, Fax +46 31343 2426, E-Mail niklas.mattsson@neuro.gu.se 
Table 1. Predictive values of diagnostic test with $95 \%$ sensitivity and $95 \%$ specificity in a population with $2 \%$ prevalence of incipient $\mathrm{AD}$

\begin{tabular}{lcll}
\hline & $\begin{array}{l}\text { Incipient AD } \\
(\mathrm{n}=2,000)\end{array}$ & $\begin{array}{l}\text { Other } \\
(\mathrm{n}=98,000)\end{array}$ & Predictive values \\
\hline Positive test & 1,900 & 4,900 & $\begin{array}{l}\text { PPV: } \\
1,900 / 6,800=28 \%\end{array}$ \\
Negative test & 100 & 93,100 & $\begin{array}{l}\text { NPV: } \\
93,100 / 93,200=99.9 \%\end{array}$ \\
\end{tabular}

the aim of performing a forward-looking individual risk assessment. Thus, what clinicians need to know are the predictive values of the test. The positive predictive value (PPV) is the ratio of true positives to all positive test results (including false positives), i.e., what percentage of the patients with a positive test result that really do have the disease. Similarly, the negative predictive value (NPV) is the ratio of true negatives to the total number of negative test results. While sensitivity and specificity depend on test characteristics in the laboratory, predictive values are influenced in a very powerful manner by the prevalence of the disease among those tested. When testing patients with MCI, which is a common patient group at the memory clinics of today, CSF biomarkers for AD have good or excellent predictive values of $80-95 \%[6,10]$, and hence they are clinically useful in this setting.

However, the neurodegenerative process is likely well under way in $\mathrm{MCI}$ patients with incipient AD. Indeed, it probably starts many years before the debut of symptoms and a large part of the neural loss may actually have taken place already before symptom onset. Treating MCI patients admitted to memory clinics will therefore only constitute a secondary prevention of $\mathrm{AD}$. If effective disease-modifying treatment becomes available, it will give rise to an urge for primary prevention, trying to avoid the development of disease. Being presymptomatic, such prevention can only be achieved by utilizing a screening program in the middle-aged or in the young elderly.

\section{General Population Screening}

Which are the prerequisites of such a screening program, and how must effective diagnostic tools be developed for such purposes? The answers to these questions will depend partly on the efficacy, tolerability and cost of the putative treatments. However, as reasoned above, es-
Table 2. Predictive values of diagnostic test with $99 \%$ sensitivity and $99 \%$ specificity in a population with $2 \%$ prevalence of incipient $\mathrm{AD}$

\begin{tabular}{lccl}
\hline & $\begin{array}{l}\text { Incipient AD } \\
(\mathrm{n}=2,000)\end{array}$ & $\begin{array}{l}\text { Other } \\
(\mathrm{n}=98,000)\end{array}$ & Predictive values \\
\hline Positive test & 1,980 & 980 & $\begin{array}{l}\text { PPV: } \\
1,980 / 2,960=67 \%\end{array}$ \\
Negative test & 20 & 97,020 & $\begin{array}{l}\text { NPV: } \\
97,020 / 97,040=99.9 \%\end{array}$ \\
& & &
\end{tabular}

tablishing the prevalence of incipient $\mathrm{AD}$ in the screened population will also be crucial. Since the exact presymptomatic duration is unknown, this is prone to speculation. In the following, we calculate with an average disease period of 5-10 years before any cognitive symptoms. This is supported by imaging as well as CSF biomarker studies [14-16]. Studies in presymptomatic carriers of familial AD mutations suggest that this period may be even longer [17]. The prevalence of dementia in people 70 years old varies in different regions, but is around 3.3\% in Europe and North America, where after it increases to 25$30 \%$ in people aged $>85$ years [18]. The most common cause of dementia is $\mathrm{AD}$, representing around $60 \%$ of dementia cases [19]. The prevalence of presymptomatic AD in people aged 60 years may therefore be estimated to be $2 \%$. Adapting a diagnostic test with excellent $95 \%$ sensitivity and $95 \%$ specificity in this population will result in a very high NPV (99.9\%) but a low PPV (28\%) (table 1). This means that the test will be useful for ruling out incipient $\mathrm{AD}$, but a positive answer will still in most cases indicate a person without AD. A diagnostic test with $99 \%$ sensitivity and $99 \%$ specificity, i.e. far better than the currently available tests including pathological examination, will only result in a PPV of $67 \%$, meaning that one third of patients tested positive will not have AD (table 2). Although troublesome, these are figures approaching the efficacy of breast cancer screening, where the rate of false positives has been approximated to one third [20].

So, how can we optimize the clinical usefulness of diagnostic tests with this accuracy? If a general screening program in 60-year-olds is an option, there will be many false positives, indicated as in need of treatment. This might be acceptable if the treatment is harmless and inexpensive. As an example, it is generally regarded acceptable that most people who take cholesterol-lowering drugs on the basis of plasma cholesterol values above a certain cut-point will have no individual benefit of the 
Table 3. Predictive values of diagnostic test with $99 \%$ sensitivity and $99 \%$ specificity in a population with $7 \%$ prevalence of incipient $\mathrm{AD}$

\begin{tabular}{lcll}
\hline & $\begin{array}{l}\text { Incipient } \mathrm{AD} \\
(\mathrm{n}=1,000)\end{array}$ & $\begin{array}{l}\text { Other } \\
(\mathrm{n}=14,000)\end{array}$ & Predictive values \\
\hline Positive test & 990 & 140 & $\begin{array}{l}\text { PPV: } \\
990 / 1,130=88 \%\end{array}$ \\
Negative test & 10 & 13,860 & $\begin{array}{l}\text { NPV: } \\
13,860 / 13,870=99.9 \%\end{array}$
\end{tabular}

The total number of studied subjects is 15,000 , representing the number of $A P O E \& 4$ carriers in a population of 100,000 symptom-free 60-year-old persons.

treatment in the absence of other risk factors for cardiovascular disease [21]. If the treatment has significant side effects or is very expensive, care must be taken to implement a follow-up test of high specificity to confirm a positive test result. It is at present unclear what such an evaluation might exactly look like in presymptomatic, biomarker-positive individuals, warranting more research.

Another way around the problem would be to postpone screening including only older individuals, where the prevalence is higher. But this will delay diagnosis in younger patients who, it might be argued, are in most need of treatment in order to preserve working capability and social function. Since AD prevalence increases with age, screening would probably be repetitive, much like screening for breast cancer or cervix cancer is done today. Calculating with a 10-year latency phase, a screening program could for example consist of testing every 3 rd to 7 th year from the age of 60 . However, in lower age categories, efforts must still be taken to enrich test populations with AD cases.

\section{Specific Population Screening}

How about considering APOE genotypes? The APOE $\varepsilon 4$ carrier rate in the general population is approximately $26 \%$ [22]. One study examining the carrier rate in $\mathrm{AD}$ patients and healthy controls in different ages found an $A P O E \varepsilon 4$ carrier rate of $15 \%$ in 60 -year-old healthy controls and $50 \%$ in 70 -year-old AD patients [23]. Thus, a group of 10,000 symptom-free 60 -year-old persons will include 1,500 APOE $\varepsilon 4$ carriers, and 100 of these will have incipient $\mathrm{AD}$ (prevalence $2 \%$ and $A P O E \varepsilon 4$ carrier rate $50 \%$ ). Using a diagnostic test with $99 \%$ sensitivity and $99 \%$ specificity on these individuals yields a PPV of $88 \%$ and an NPV of $99.9 \%$ (table 3). The major hitch with this strategy is of course the exclusion of the $50 \%$ of incipient $\mathrm{AD}$ patients aged 60 years not carrying the $A P O E$ $\varepsilon 4$ allele. If such a screening strategy should be successful it therefore requires including all individuals in the following screening rounds, irrespectively of $A P O E$ genotype.

In sum, it is not unlikely that we will have access to disease-modifying treatments of $\mathrm{AD}$ within a reasonably near future. How these treatments should be applied will invoke political and medical questions of considerable importance and difficulty. Powerful diagnostic tests will undoubtedly be needed, but one must also bear in mind the limitations of these tests when used in the general population. Even biomarkers with very high sensitivity and specificity must be limited to specific and well-defined clinical settings. Due to their wide implications, these questions need to be addressed well ahead by researchers developing biomarkers for neurodegenerative disorders.

\section{References}

1 Thal LJ: Prevention of Alzheimer disease. Alzheimer Dis Assoc Disord 2006;20(suppl 2):S97-S99.

$\checkmark 2$ Doody RS, Gavrilova SI, Sano M, Thomas RG, Aisen PS, Bachurin SO, Seely L, Hung D: Effect of dimebon on cognition, activities of daily living, behaviour, and global function in patients with mild-to-moderate Alzheimer's disease: a randomised, double-blind, placebo-controlled study. Lancet 2008;372: 207-215.
3 Petersen RC, Doody R, Kurz A, Mohs RC, Morris JC, Rabins PV, et al: Current concepts in mild cognitive impairment. Arch Neurol 2001;58:1985-1992.

4 Petersen RC, Smith GE, Waring SC, Ivnik RJ, Tangalos EG, Kokmen E: Mild cognitive impairment: clinical characterization and outcome. Arch Neurol 1999;56:303-308.

5 Blennow K, Hampel H: CSF markers for incipient Alzheimer's disease. Lancet Neurol 2003;2:605-613.
6 Zetterberg H, Wahlund LO, Blennow K: Cerebrospinal fluid markers for prediction of Alzheimer's disease. Neurosci Lett 2003;352: 67-69.

7 Riemenschneider M, Lautenschlager N, Wagenpfeil S, Diehl J, Drzezga A, Kurz A: Cerebrospinal fluid $\tau$ and $\beta$-amyloid- 42 proteins indentify Alzheimer's disease in subjects with mild cognitive impairment. Arch Neurol 2002;59:1729-1734. 
8 Herukka SK, Helisalmi S, Hallikainen M, Tervo S, Soininen H, Pirttilä T: CSF A $\beta 42, \tau$ and phosphorylated $\tau$, APOE $\varepsilon 4$ allele and MCI type in progressive MCI. Neurobiol Aging 2007;28:507-514.

$\checkmark 9$ Andreasen N, Minthon L, Vanmechelen E, Vanderstichele H, Davidsson P, Winblad B, Blennow K: Cerebrospinal fluid $\tau$ and $A \beta 42$ as predictors of development of Alzheimer's disease in patients with mild cognitive impairment. Neurosci Lett 1999;273:5-8.

$\checkmark 10$ Hansson O, Zetterberg H, Buchhave P, Londos E, Blennow K, Minthon L: Association between CSF biomarkers and incipient Alzheimer's disease in patients with mild cognitive impairment: a follow-up study. Lancet Neurol 2006;5:228-234.

-11 Maruyama M, Matsui T, Tanji H, Nemoto M, Tomita N, Ootsuki M, Arai H, Sasaki H: Cerebrospinal fluid $\tau$ protein and periventricular white matter lesions in patients with mild cognitive impairment: implications for two major pathways. Arch Neurol 2004;61:716720 .

-12 Bouwman FH, Schoonenboom SN, van der Flier WM, van Elk EJ, Kok A, Barkhof F, Blankenstein MA, Scheltens P: CSF biomarkers and medial temporal lobe atrophy predict dementia in mild cognitive impairment. Neurobiol Aging 2007;28:1070-1074.
3 Grimes DA, Schulz KF: Uses and abuses of screening tests. Lancet 2002;359:881-884.

14 Carlson NE, Moore MM, Dame A, Howieson D, Silbert LC, Quinn JF, Kaye JA: Trajectories of brain loss in aging and the development of cognitive impairment. Neurology 2008;70:828-833.

15 Fagan AM, Roe CM, Xiong C, Mintun MA, Morris JC, Holtzman DM: Cerebrospinal fluid $\tau / \beta$-amyloid-42 ratio as a prediction of cognitive decline in non-demented older adults. Arch Neurol 2007;64:343-349.

16 Gustafson DR, Skoog I, Rosengren L, Zetterberg $\mathrm{H}$, Blennow K: Cerebrospinal fluid $\beta$ amyloid-1-42 concentration may predict cognitive decline in older women. J Neurol Neurosurg Psychiatry 2007;78:461-464.

17 Ringman JM, Younkin SG, Pratico D, Seltzer W, Cole GM, Geschwind DH, RodriguezAgudelo Y, Schaffer B, Fein J, Sokolow S, Ro sario ER, Gylys KH, Varpetian A, Medina LD, Cummings JL: Biochemical markers in persons with preclinical familial Alzheimer disease. Neurology 2008;71:85-92.
18 Ferri CP, Prince M, Brayne C, Brodaty H, Fratiglioni L, Ganguli M, Hall K, Hasegawa K, Hendrie H, Huang Y, Jorm A, Mathers C, Menezes PR, Rimmer E, Scazufca M: Alzheimer's Disease International. Global prevalence of dementia: a Delphi consensus study. Lancet 2005;366:2112-2117.

19 Blennow K, de Leon MJ, Zetterberg H: Alzheimer's disease. Lancet 2006;368:387-403.

20 Elmore JG, Barton MB, Moceri VM, Polk S, Arena PJ, Fletcher SW: Ten-year risk of false positive screening mammograms and clinical breast examinations. N Engl J Med 1998; 338:1089-1096.

21 Ward S, Lloyd Jones M, Pandor A, Holmes M, Ara R, Ryan A, Yeo W, Payne N: A systematic review and economic evaluation of statins for the prevention of coronary events. Health Technol Assess 2007;11:1-160, iii-iv.

-22 Menzel HJ, Kladetzky RG, Assmann G: Apolipoprotein E polymorphism and coronary artery disease. Arteriosclerosis 1983;3:310315.

-23 Frisoni GB, Manfredi M, Geroldi C, Binetti G, Zanetti O, Bianchetti A, Trabucchi M. The prevalence of APOE-4 in Alzheimer's disease is age dependent. J Neurol Neurosurg Psychiatry 1998;65:103-106. 